\title{
Laparoscopic Nephroureterectomy and Management of the Distal Ureter: A Review of Current Techniques and Outcomes
}

\author{
Davis P. Viprakasit, Amanda M. Macejko, and Robert B. Nadler \\ Department of Urology, Feinberg School of Medicine, Northwestern University, Chicago, IL 60208, USA \\ Correspondence should be addressed to Robert B. Nadler, r-nadler@northwestern.edu
}

Received 27 May 2008; Accepted 3 November 2008

Recommended by Norm D. Smith

\begin{abstract}
Laparoscopic nephroureterectomy (LNU) is becoming an increasingly common alternative treatment for transitional cell carcinoma (TCC) of the renal pelvis and ureter due to decreased perioperative morbidity, shorter hospitalization, and comparable oncologic control with open nephroureterectomy (ONU). Mobilization of the kidney and proximal ureter may be performed through a transperitoneal, retroperitoneal, or hand-assisted approach. Each technique is associated with its own benefits and limitations, and the optimal approach is often dictated by surgeon preference. Our analysis of the literature reflects equivalent cancer control between LPN and OPN at intermediate follow-up with significantly improved perioperative morbidity following LPN. Several methods for bladder cuff excision have been advocated, however, no individual technique for management of the distal ureter proved superior. Overall, complete en-bloc resection with minimal disruption of the urinary tract should be optimized to maintain oncologic outcomes. Longer follow-up and prospective studies are needed to fully evaluate these techniques.
\end{abstract}

Copyright (C) 2009 Davis P. Viprakasit et al. This is an open access article distributed under the Creative Commons Attribution License, which permits unrestricted use, distribution, and reproduction in any medium, provided the original work is properly cited.

\section{Introduction}

Transitional cell carcinoma (TCC) of the renal pelvis and ureter is a disease associated with high propensity for tumor recurrence and progression. Open radical nephroureterectomy (ONU) with bladder cuff excision is the traditional standard treatment for most localized diseases of the upper urinary tract because of its aggressive nature, as well as the difficulty encountered with surveillance of the upper tract urothelium [1]. To obtain adequate exposure, open excision of the distal ureter and bladder cuff requires either two skin incisions or an extended flank incision. This is associated with increased perioperative morbidity and recovery time. First described by Clayman et al. in 1991 [2], laparoscopic radical nephroureterectomy (LNU) has shown significant advantages in terms of blood loss, postoperative pain and recovery time, as well as comparable short and intermediateterm oncologic outcomes with the open treatment [3]. As more urologists are gaining increased comfort with minimally invasive techniques, LNU exhibits a large growth in worldwide popularity [4]. However, the optimal laparoscopic approach for nephroureterectomy as well as the technique for addressing the bladder cuff is unclear. We present a review of the most recent literature detailing the perioperative and cancer control outcomes observed with the various methods of LNU and discuss the reported variations on bladder cuff excision.

\section{Laparoscopic Nephroureterectomy}

2.1. Approach. A variety of techniques have been utilized to perform mobilization of the kidney and proximal ureter. These include conventional transperitoneal, conventional retroperitoneal, hand-assisted transperitoneal, and handassisted retroperitoneal approaches. The choice of laparoscopic approach is most dependent on the comfort level and training of the surgeon. However, each technique has its own potential advantages. Transperitoneal exposure offers the largest working area and may be beneficial for extensive tumors or lymphadenopathy. The retroperitoneal approach, however, involves decreased bowel manipulation and potentially allows for earlier recovery of bowel function. Additionally, this method may be favored in morbidly obese patients with an obstructing pannus or in patients with 
a history of previous transperitoneal surgeries [5]. Handassistance techniques allow for continued tactile sensation and may lessen the learning curve required in laparoscopy [6]. Most of the experiences with LNU are primarily reported as single-institutional retrospective series. To date, there have been no prospective randomized studies that compare the different techniques for LNU. However, data published in the laparoscopic radical nephrectomy literature may be applicable. For example, a randomized, prospective study comparing conventional transperitoneal, retroperitoneal, and handassisted transperitoneal laparoscopic radical nephrectomy was recently published [7]. The hand-assisted technique resulted in a significantly shorter operative time but an increased risk of hernia formation; conversely, conventional transperitoneal surgery was associated with significantly improved perioperative morbidity. Desai et al. reported shorter operative times and faster control of the renal vasculature with retroperitoneal approaches in a prospective randomized comparison of conventional transperitoneal and retroperitoneal laparoscopic radical nephrectomy but no significant differences in other perioperative measures [5].

2.2. Perioperative Outcomes. Rassweiler et al. performed a literature review of published studies between 1991 and 2004 of LNU and ONU, including nine comparative studies and 1365 overall patients [3]. As compared to ONU, LNU was associated with a slightly longer operative time (277 versus 220 minutes), significantly lower blood loss (241 versus $463 \mathrm{~mL}$ ), and shorter hospital stays, but showed similar complication rates ( $18 \%$ versus $21 \%$ ).

Table 1 summarizes the perioperative outcomes of 12 LNU studies published since 2005. The mean operating time ranged from 165 to 395 minutes (mean 271) in the laparoscopic group ( $n=465$ patients), and 155 to 313 minutes (mean 237) in the open group ( $n=268$ patients). Significantly increased operative time with laparoscopy was noted in three of eight comparative studies, all of which involved the retroperitoneal approach. The blood loss averaged between 183 to $497 \mathrm{~mL}$ (mean 279) in the laparoscopic group as compared to a range of 296 to $558 \mathrm{~mL}$ (mean 402 ) in the open group. Significantly less blood loss after laparoscopy was noted in four of eight comparative studies with a similar trend in three of the remaining studies. The overall complication rate ranged from 0 to $37 \%$ (mean 18\%) in the laparoscopy group and from 0 to $15 \%$ (mean $7 \%$ ) in the open group. The open conversion rate associated with laparoscopy ranged from 0 to $10 \%$. The absolute duration of hospital stays varied between institutions. Out of eight comparative studies, hospitalization following laparoscopy was shorter in seven series with a significant difference in five.

2.3. Oncologic Outcomes. The highly aggressive natural history of upper tract TCC, particularly with high-grade and high-stage disease, likely contributes to its increased potential for recurrence and poor prognosis irrespective of the surgical technique. However, there are many concerns that technical aspects of LNU, particularly with regard to management of the distal ureter and bladder cuff, may affect recurrence risks in the bladder, locally, or as port-site metastases secondary to tumor seeding. Rassweiler et al. noted no significant difference in bladder recurrence (24\% versus $25 \%$ ), local recurrence $(4 \%$ versus $6 \%$ ) and distant metastases $(15.5 \%$ versus $15.2 \%$ ) in eight LNU series and 11 ONU series [3]. The 2-year cancer specific survival rates were also similar (75\% versus $76 \%)$.

Table 2 summarizes the short and intermediate oncologic outcomes of $14 \mathrm{LNU}$ studies published since 2005. The most common method for bladder cuff excision was an open approach. At a minimum median follow-up of at least 2 years, bladder recurrence after LNU ( $n=488$ patients) ranged from 10 to $55 \%$ (mean $30 \%$ ) as compared to 15 to $55 \%$ (mean 33\%) in the ONU series $(n=512$ patients). Local recurrence in the retroperitoneum was documented as 0 to $13 \%$ (mean 3.3\%) in the laparoscopic ( $n=588$ patients) and 0 to $8 \%$ (mean $2.5 \%)$ in the open series $(n=512$ patients). Distant metastases occurred in 0 to $18 \%$ (mean $9.5 \%)$ of patients undergoing $\mathrm{LNU}(n=588$ patients $)$ as compared to 5 to $35 \%$ (mean $14.5 \%$ ) in the open series ( $n=512$ patients). In six series reporting 2-year diseasespecific survival, the rates ranged from 64 to $91 \%$ (mean $83 \%)$ in the laparoscopic series $(n=274$ patients $)$ and between 58 to $93 \%$ (mean 83.6\%) after ONU $(n=242$ patients). In the five series reporting 5 -year survival rates, the outcomes ranged from 68 to $90 \%$ (mean $85 \%$ ) after LNU ( $n=202$ patients) and 62 to $86 \%$ (mean 75\%) in the ONU groups ( $n=191$ patients). There was no significant difference between LNU and ONU survival rates in the 10 comparative studies. However, absolute comparisons between the surgical approaches are difficult as the percentage of patients with high-grade disease and the follow-up period varied considerably, reflecting a large limitation with the retrospective nature of these studies. In addition, the inclusion of patients with a prior or concomitant history of bladder cancer may affect the oncologic outcome of treating upper tract TCC. In the 14 LNU studies, only 7 addressed this parameter in defining their patient characteristics. The 4 comparative studies including such patients and the 1 study which excluded patients with bladder TCC did not show a significant difference between ONU and LNU groups. However, it is unclear if the underlying biology and tumor aggressiveness in patients with both upper and lower tract TCC differ from patients with isolated upper tract TCC; inclusion of such patients in studies with already relatively low numbers further complicates comparisons of treatment approach.

2.4. Port-Site Metastases. One unique concern reported following laparoscopic surgery is the occurrence of recurrent malignant disease at the port-site [22]. To the best of our knowledge, there have been 18 cases published in the literature of port-site metastases of upper tract TCC after laparoscopy (Table 3). In seven cases, the diagnosis of TCC was not suspected preoperatively which influenced the surgical technique. Metastases occurred 3 to 15 months postoperatively (mean 6.8). These overall experiences emphasize that general preventive measures should be undertaken at 
TABLE 1: Perioperative characteristics of LPN versus ONU cases. CR, conventional retroperitoneal; CT, conventional transperitoneal; HAT, hand-assisted transperitoneal; NL, not listed; ONU, open nephroureterectomy.

\begin{tabular}{|c|c|c|c|c|c|c|c|c|}
\hline Author & Surgery & Number & $\begin{array}{l}\text { High } \\
\text { grade } \\
(\%) \\
\end{array}$ & $\begin{array}{l}\text { OR } \\
\text { duration } \\
(\min )\end{array}$ & $\begin{array}{l}\text { Blood } \\
\text { loss } \\
(\mathrm{min})\end{array}$ & $\begin{array}{l}\text { Conversion } \\
(\%)\end{array}$ & $\begin{array}{l}\text { Complication } \\
(\%)\end{array}$ & Hospital days \\
\hline Muntener et al. [8] & $\mathrm{CT}$ & 39 & $31(80)$ & 312 & 300 & $4(10)$ & $12(31)$ & 4 \\
\hline Schatteman et al. [9] & CT & 100 & $48(48)$ & 192 & 234 & $7(7)$ & $19(19)$ & 10 \\
\hline \multirow{2}{*}{ Rouprêt et al. [10] } & $\mathrm{CT}$ & 20 & $8(40)$ & 165 & 275 & $1(5)$ & $3(15)$ & 4 \\
\hline & ONU & 26 & $19(73)$ & 155 & 338 & - & $4(15)$ & 9 \\
\hline \multirow{2}{*}{ Okegawa et al. [11] } & CR & 25 & $6(24)$ & 299 & 258 & $1(4)$ & $4(16)$ & 11 \\
\hline & ONU & 23 & $7(30)$ & 313 & 403 & - & $3(13)$ & 13 \\
\hline \multirow{2}{*}{ Tsujihata et al. [12] } & $\mathrm{CR}$ & 25 & $5(20)$ & 306 & 322 & $0(0)$ & $0(0)$ & 2 \\
\hline & ONU & 24 & $12(50)$ & 271 & 558 & - & $0(0)$ & 4 \\
\hline \multirow{2}{*}{ Taweemonkongsap et al. [13] } & CR & 31 & $13(42)$ & 259 & 289 & $0(0)$ & $2(6)$ & 9.3 \\
\hline & ONU & 29 & $19(66)$ & 191 & 314 & - & $2(7)$ & 8.7 \\
\hline \multirow{2}{*}{ Chung et al. [14] } & HAT & 39 & $16(41)$ & 233 & 183 & $0(0)$ & $5(13)$ & 7 \\
\hline & ONU & 36 & $15(42)$ & 220 & 422 & - & $3(8)$ & 9 \\
\hline \multirow{2}{*}{ Raman et al. [15] } & HAT & 38 & $15(40)$ & 244 & 191 & $0(0)$ & $4(11)$ & 5 \\
\hline & ONU & 52 & $19(37)$ & 243 & 478 & 一 & $2(4)$ & 7 \\
\hline Wolf et al. [16] & HAT & 53 & $26(49)$ & 279 & 330 & $1(2)$ & $20(37)$ & 4 \\
\hline Cannon et al. [17] & HAT & 34 & NL & 317 & 252 & $0(0)$ & $9(26)$ & 8 \\
\hline \multirow{2}{*}{ Chung et al. [18] } & HAR & 25 & $11(44)$ & 252 & 212 & $0(0)$ & $3(12)$ & 6.5 \\
\hline & ONU & 41 & $17(41)$ & 212 & 408 & - & $3(7)$ & 9 \\
\hline \multirow{2}{*}{ Nakashima et al. [19] } & HAR & 36 & $18(50)$ & 395 & 497 & $1(3)$ & $11(31)$ & 18.8 \\
\hline & ONU & 37 & $13(35)$ & 289 & 296 & - & $2(5)$ & 19.1 \\
\hline
\end{tabular}

the conclusion of the surgery including the use of an impermeable organ bag, minimal tissue handling, and the avoidance of gross violation of the urinary system until the specimen has been removed en bloc.

\section{Bladder Cuff Excision}

There is no consensus as to the optimal technique to excise the distal ureter and ipsilateral bladder cuff [1]. Definitive steps to minimize tumor seeding and complete excision of the ureter are mandatory given the $30 \%$ to $64 \%$ tumor recurrence rate reported following inadequate distal resections [31, 32]. As noted in Table 2, one of the most utilized approaches involves an open approach. This may be accomplished transvesically or extravesically via a lower midline, Pfannenstiel, or Gibson incision, or by incorporation of the hand port incision following handassisted LNU. This technique is similarly employed during ONU and offers the surgeon familiarity, direct visualization, and a simultaneous site for en bloc specimen extraction. Awareness of the contralateral trigone and ureteral orifice location should be undertaken as potential injury may occur during ipsilateral dissection or bladder cuff closure [33].

Alternatively, numerous endoscopic approaches have been promoted. In 1952, McDonald et al. described the first endoscopic method of bladder cuff excision, the "pluck" technique, via transurethral resection of the ureteral orifice
(TURUO) at the onset of surgery [34]. Resection of the orifice and intramural ureter, however, may require patient repositioning and when performed at the onset of the procedure can expose the extravesical space to potential tumor seeding. Several modifications have been described to this technique in contemporary series, including delaying resection until after kidney mobilization, performing transvesical endoscopy [35] or using transurethral cystoscopy with a Bugbee electrode [36] or Collins knife for excision [37]. Ko et al. reviewed their experience comparing open dissection ( $n=27$ patients) with modified TURUO using a Collins knife ( $n=19$ patients) following nephroureterectomy [38]. At a mean follow-up of over 22 months, they noted similar bladder recurrence rates (22.2\% versus $26.3 \%)$ without evidence of pelvic recurrence.

The technique of ureteral intussusception has also been described and involves endoscopic extraction of the ligated ureter using a "stripping" method with the assistance of a ureteral catheter [39]. However, this approach is contraindicated with concomitant bladder or ureteral tumors and was noted to have an incomplete excision rate of $18.7 \%$ in a large single institutional series of 32 patients [40].

Gill et al. described the method of cystoscopic detachment and ligation which incorporates intramural ureteral dissection with a Collins knife aided by two transvesical laparoscopic ports and an endoloop to ligate the ureteral lumen and minimize potential tumor spillage [41]. While this method most closely echoes the intentions of ONU, it 


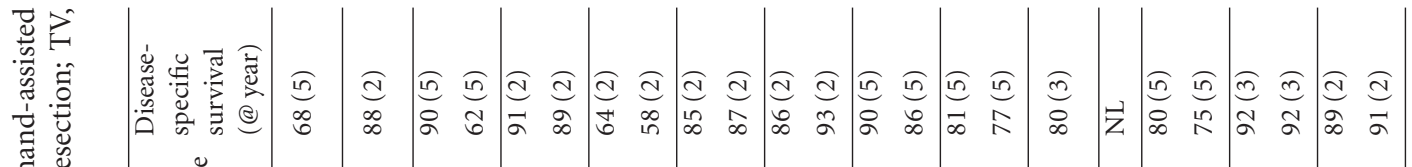

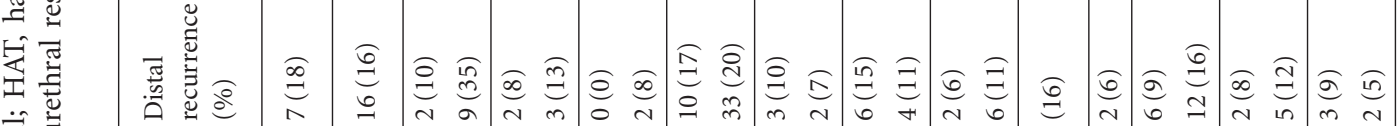

苟

峁

要要

?

苞: 苛

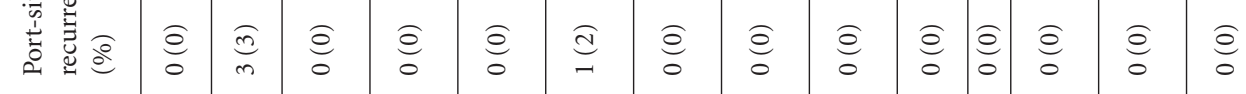

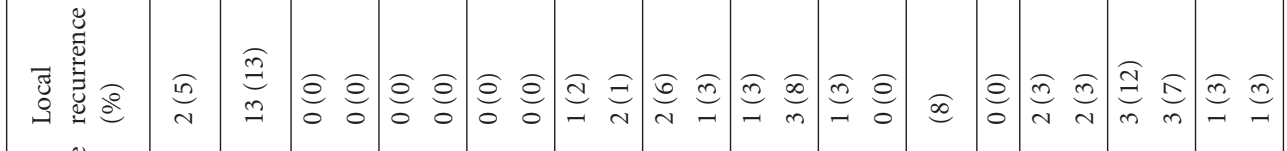

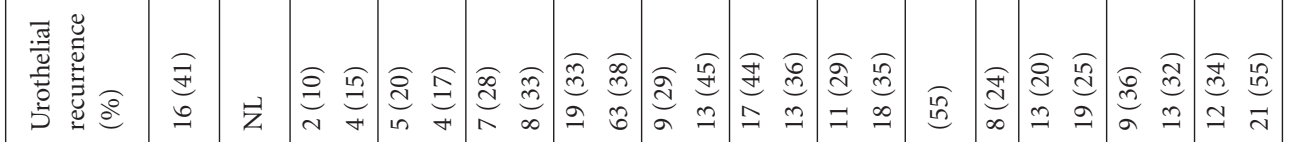

空突

馬

.气े

空

藏

. 艺

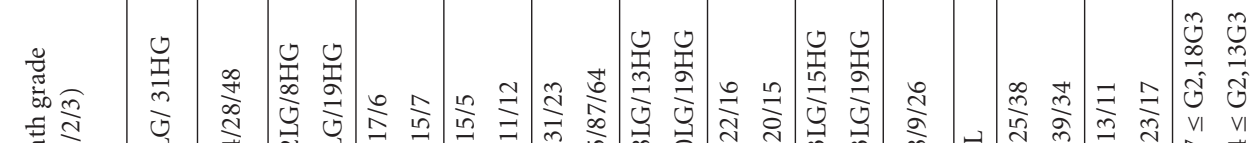

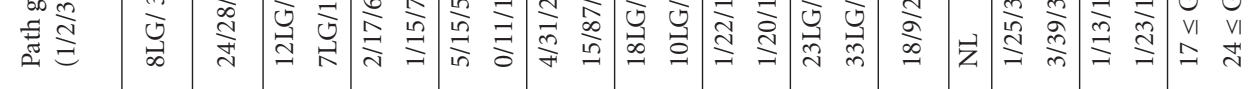

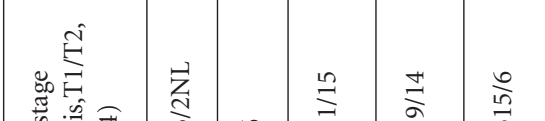

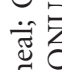

营

원

沓

苞

ठํํㅇ

글

峁

ปี

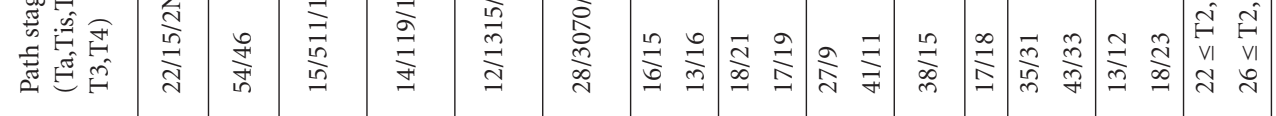

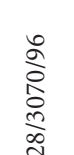

$\stackrel{m}{m} \underset{g}{\stackrel{g}{g}}$

Zn

窎言

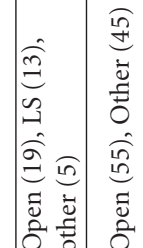

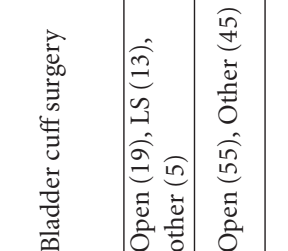

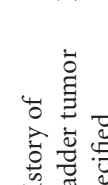

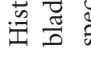

节

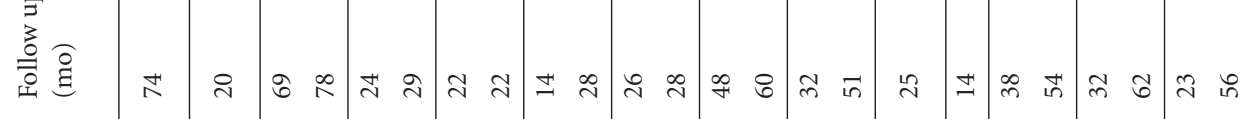

只:

㫕 :

若

冚

.

응

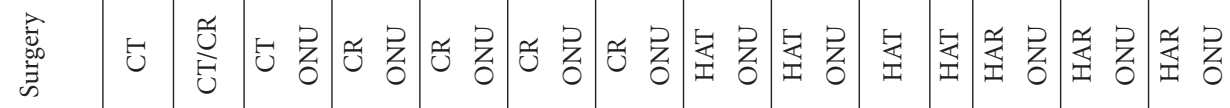

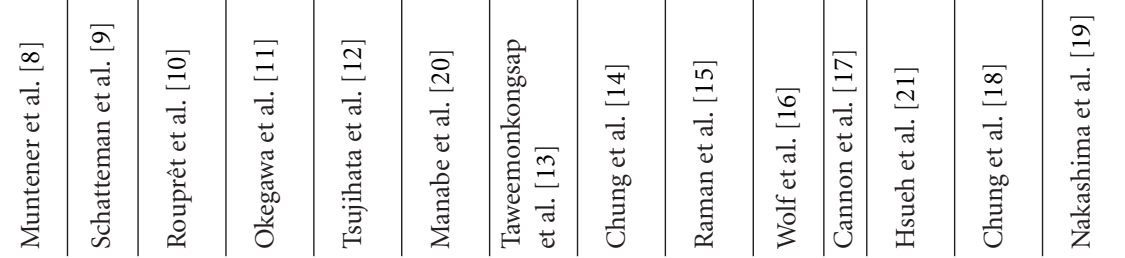


TABle 3: Port-site metastasis following LNU. CR, conventional retroperitoneal; CT, conventional transperitoneal; HAT, hand-assisted transperitoneal; LNU, laparoscopic nephroureterectomy; NL, not listed; TCC, transitional cell carcinoma; TURBT, transurethral resection of bladder tumor.

\begin{tabular}{|c|c|c|c|c|c|c|}
\hline Author & Surgery & Stage & Retrieval bag & Metastases location & Time to metastasis (mo) & Comments \\
\hline Ahmed et al. [23] & $\mathrm{CT}$ & pT3 & No & Widespread & 8 & \\
\hline Barrett et al. [24] & CT & pT1 & No & Widespread & $\mathrm{NL}$ & \\
\hline Otani et al. [25] & $\mathrm{CT}$ & pT3 & Yes & Trocar & 3 & $\begin{array}{l}\text { Bag torn; preoperative diagnosis of } \\
\text { TCC not known }\end{array}$ \\
\hline Ong et al. [26] & $\mathrm{CR}$ & $\mathrm{pT} 1$ & Yes & Trocar & 12 & $\begin{array}{l}\text { Stent perforation in proximal } \\
\text { ureter noted at time of LNU }\end{array}$ \\
\hline Chueh et al. [27] & HAT & pT2 & $\mathrm{NL}$ & Trocar & 8 & $\begin{array}{l}\text { Bilateral LNU and TURBT } \\
\text { performed in renal transplant } \\
\text { patient }\end{array}$ \\
\hline Micali et al. [28] & CT & pT3 & Yes & $\mathrm{NL}$ & 3 & \\
\hline Micali et al. [28] & $\mathrm{CR}$ & pT3 & Yes & $\mathrm{NL}$ & 15 & \\
\hline Micali et al. [28] & HAT & pT3 & Yes & $\mathrm{NL}$ & 3 & \\
\hline Micali et al. [28] & CR & $\mathrm{pT} 1$ & No & Trocar & 3 & $\begin{array}{l}\text { Preoperative diagnosis of TCC not } \\
\text { known }\end{array}$ \\
\hline Micali et al. [28] & $\mathrm{CR}$ & $\mathrm{pT} 1$ & Yes & Trocar & $\mathrm{NL}$ & $\begin{array}{l}\text { Preoperative diagnosis of TCC not } \\
\text { known }\end{array}$ \\
\hline Micali et al. [28] & $\mathrm{CR}$ & $\mathrm{pT} 2$ & Yes & Trocar & $\mathrm{NL}$ & $\begin{array}{l}\text { Preoperative diagnosis of TCC not } \\
\text { known }\end{array}$ \\
\hline Micali et al. [28] & $\mathrm{CR}$ & $\mathrm{NL}$ & Yes & Trocar & $\mathrm{NL}$ & $\begin{array}{l}\text { Preoperative diagnosis of TCC not } \\
\text { known }\end{array}$ \\
\hline Matsui et al. [29] & $\mathrm{CR}$ & pT3 & No & Trocar & 6 & Squamous cell carcinoma \\
\hline Naderi et al. [30] & $\mathrm{CT}$ & pT2 & No & $\begin{array}{l}\text { Trocar, subcostal } \\
\text { wound }\end{array}$ & 3 & $\begin{array}{l}\text { Required conversion to open } \\
\text { surgery secondary to renal vein } \\
\text { bleeding }\end{array}$ \\
\hline Manabe et al. [20] & $\mathrm{CR}$ & $\mathrm{NL}$ & NL & Widespread & NL & $\begin{array}{l}\text { Urine extravasation secondary to } \\
\text { urinary tract obstruction noted } \\
\text { preop }\end{array}$ \\
\hline Schatteman et al. [9] & CT & pT4 & No & Widespread & 5 & $\begin{array}{l}\text { Preoperative diagnosis of TCC not } \\
\text { known }\end{array}$ \\
\hline Schatteman et al. [9] & $\mathrm{CT}$ & pT3 & No & Widespread & 8 & $\begin{array}{l}\text { Preoperative diagnosis of TCC not } \\
\text { known }\end{array}$ \\
\hline Schatteman et al. [9] & $\mathrm{CT}$ & pT1 & Yes & Widespread & 11 & \\
\hline
\end{tabular}

is associated with a steep learning curve and long procedural time [42].

Laparoscopic stapling of the distal ureter and bladder cuff with either cystoscopic unroofing or a pure extravesical approach has also been utilized [43]. This technique, however, has been associated with the potential risk of stone formation [44] or viable tumor cells within the incorporated staple line [45]. A comparison of laparoscopic stapling (20\% of cohort) with cystoscopic detachment and ligation $(60 \%$ of cohort) by Matin and Gill was notable for a positive surgical margin rate of $25 \%$ versus $2.8 \%$ [46]. Hattori et al. reported their experience between laparoscopic stapling and open bladder cuff excision [44]. They noted a significantly decreased operative time with laparoscopic stapling with no significant difference in bladder and extravesical recurrencefree rates and disease-specific survival at 3-year follow-up. Tsivian et al. detailed a modified technique for excising the periurethral bladder cuff en bloc using a LigaSure Atlas device instead of a stapler [47]. Similarly, excision via harmonic scalpel has also been utilized [48]. Division of the bladder cuff using hemostatic diathermy devices may address the potential concerns of viable tumor cells and stone formation associated with laparoscopic stapling although further study is needed.

While there have been no randomized prospective trials comparing the management of the distal ureter, several groups have reported their retrospective results with several different approaches. In a large multicenter American and European study, Abou El Fettouh et al. noted that the local recurrence rates and the development of metastases depended on pathologic tumor stage and was irrespective of bladder cuff approach (open, TURUO, cystoscopic detachment and ligation, laparoscopic stapling) [49]. In a series of 55 patients undergoing hand-assisted transperitoneal LNU, Brown et al. noted increased perioperative morbidity and complications with TURUO. However, higher positive surgical margins were observed following laparoscopic stapling $(29 \%)$ or extravesical harmonic scalpel excision 
(10\%) as compared to TURUO or open techniques [50]. Additionally, in patients without active or recent lower tract TCC, concerns exist regarding the increased potential risk of local recurrence when the cystotomy is not primarily closed following excision of the ureteral orifice and bladder neck as with many of the endoscopic approaches. Brown et al. noted their sole pelvic recurrence occurred in 1 of 7 patients without cystotomy closure, leading the authors to also advocate routine bladder defect closure [50]. However, Kurzer et al. reported no local recurrences in 49 patients treated with a modified TURUO technique and no cystotomy closure at a median follow-up of 10 months [51].

\section{Role of Lymphadenectomy}

Given its aggressive nature, the presence of nodal involvement in TCC of the renal pelvis and ureter is a poor prognostic factor and has shown limited response to adjuvant therapies [52]. However, the role and utilization of routine lymph node dissection (LND) in conjunction with either LNU or ONU is not well established. This contrasts lower urinary tract TCC in which extended pelvic LND is well supported in the literature for improved staging and survival benefits [53]. One reason for the variable use of LND (Table 2) is that the standard template for regional lymph node involvement in upper tract TCC has not been well delineated. In a recent review of 42 of 181 patients with upper tract TCC metastases, Kondo et al. noted that the location of lymph node metastases depended on the laterality and level of the primary tumor [54]. Based on their findings, the authors advocated a relatively wide LND template, particularly on the right side to include the paracaval, retrocaval, and interaortocaval nodes. In a follow-up study, the authors noted an improved cancerspecific survival in patients with advanced disease (stage pT3 or higher) undergoing LND although no difference was noted when all pathologic stages were considered [55]. Brausi et al. similarly reported an improved disease-specific survival benefit in patients treated with ONU and LND $(81.6 \%)$ as compared to ONU alone (44.8\%) [56]. However, the retrospective study may have been influenced by a potential bias in patient selection for LND [57]. Additionally, regardless of the benefits of LND, concerns remain regarding the technical challenge of laparoscopic lymphadenectomy. Hattori et al. reported a significantly decreased number of lymph nodes removed following LNU (8.2-11.6) as compared to ONU (16.5) [44]. Busby and Matin, however, reported their experience that removal of an equivalent number of nodes could be performed with both laparoscopic and open approaches [58].

\section{Future Developments}

With the increased popularity in robotic-assisted laparoscopy in urology, individual case reports and small case series have recently described robotic-assisted LNU with either retroperitoneal or transperitoneal approaches [59-62]. The improved dexterity, precision, and control of robotic assistance may better facilitate handling of the distal ureter and bladder cuff [60]. However, concerns with cost and the potential need for patient repositioning and robot redocking may influence the widespread utilization of robotics in treating upper tract TCC.

\section{Conclusions}

Following the increased popularity of laparoscopy in urologic surgery, LNU has become a common treatment for TCC of the renal pelvis and ureter with decreased perioperative morbidity, shorter hospitalization, as well as comparable oncologic outcomes and survival rates as with ONU. The optimal technique for mobilization of the kidney and proximal ureter, as well as excision of the distal ureter and bladder cuff, is still evolving and largely based on surgeon preference. The classic open approach for distal ureter removal is most comparable to the established principles of open oncologic surgery and simultaneously allows for intact en bloc specimen removal. Regardless of technique used, minimal disruption of the urinary tract should be maintained to decrease the risk of recurrences and portsite metastases. The role of routine lymphadenectomy and the utilization of robotic assistance in upper urinary tract TCC are still to be determined. Long-term studies with prospective, randomized trials are necessary to fully evaluate the outcomes of LNU in the management of this aggressive disease.

\section{References}

[1] W. Oosterlinck, E. Solsona, A. P. M. van der Meijden, et al., "EAU guidelines on diagnosis and treatment of upper urinary tract transitional cell carcinoma," European Urology, vol. 46, no. 2, pp. 147-154, 2004.

[2] R. V. Clayman, L. R. Kavoussi, R. S. Figenshau, P. S. Chandhoke, and D. M. Albala, "Laparoscopic nephroureterectomy: initial clinical case report," Journal of Laparoendoscopic Surgery, vol. 1, no. 6, pp. 343-349, 1991.

[3] J. J. Rassweiler, M. Schulze, R. Marrero, T. Frede, J. Palou Redorta, and P. Bassi, "Laparoscopic nephroureterectomy for upper urinary tract transitional cell carcinoma: is it better than open surgery?” European Urology, vol. 46, no. 6, pp. 690-697, 2004.

[4] G. S. Gerber and B. R. Stockton, "Update on laparoscopic nephrectomy and nephroureterectomy," Journal of Endourology, vol. 19, no. 10, pp. 1151-1153, 2005.

[5] M. M. Desai, B. Strzempkowski, S. F. Matin, et al., "Prospective randomized comparison of transperitoneal versus retroperitoneal laparoscopic radical nephrectomy," The Journal of Urology, vol. 173, no. 1, pp. 38-41, 2005.

[6] J. Landman, R. Y. Lev, S. Bhayani, et al., "Comparison of hand assisted and standard laparoscopic radical nephroureterectomy for the management of localized transitional cell carcinoma," The Journal of Urology, vol. 167, no. 6, pp. 2387-2391, 2002.

[7] R. B. Nadler, S. Loeb, J. Q. Clemens, R. A. Batler, C. M. Gonzalez, and I. Y. Vardi, "A prospective study of laparoscopic radical nephrectomy for T1 tumors-is transperitoneal, retroperitoneal or hand assisted the best approach?" The Journal of Urology, vol. 175, no. 4, pp. 1230-1234, 2006. 
[8] M. Muntener, M. E. Nielsen, F. R. Romero, et al., "Long-term oncologic outcome after laparoscopic radical nephroureterectomy for upper tract transitional cell carcinoma," European Urology, vol. 51, no. 6, pp. 1639-1644, 2007.

[9] P. Schatteman, C. Chatzopoulos, C. Assenmacher, et al., "Laparoscopic nephroureterectomy for upper urinary tract transitional cell carcinoma: results of a Belgian retrospective multicentre survey," European Urology, vol. 51, no. 6, pp. 1633-1638, 2007.

[10] M. Rouprêt, V. Hupertan, K. M. Sanderson, et al., "Oncologic control after open or laparoscopic nephroureterectomy for upper urinary tract transitional cell carcinoma: a single center experience," Urology, vol. 69, no. 4, pp. 656-661, 2007.

[11] T. Okegawa, A. Odagane, H. Ide, S. Horie, K. Nutahara, and E. Higashihara, "Oncological outcome of retroperitoneoscopic nephroureterectomy for upper urinary tract transitional cell carcinoma," International Journal of Urology, vol. 13, no. 5, pp. 493-497, 2006.

[12] M. Tsujihata, N. Nonomura, A. Tsujimura, K. Yoshimura, Y. Miyagawa, and A. Okuyama, "Laparoscopic nephroureterectomy for upper tract transitional cell carcinoma: comparison of laparoscopic and open surgery," European Urology, vol. 49, no. 2, pp. 332-336, 2006.

[13] T. Taweemonkongsap, C. Nualyong, T. Amornvesukit, et al., "Outcomes of surgical treatment for upper urinary tract transitional cell carcinoma: comparison of retroperitoneoscopic and open nephroureterectomy," World Journal of Surgical Oncology, vol. 6, article 3, pp. 1-7, 2008.

[14] S.-D. Chung, S.-C. Chueh, M.-K. Lai, et al., "Long-term outcome of hand-assisted laparoscopic radical nephroureterectomy for upper-tract urothelial carcinoma: comparison with open surgery," Journal of Endourology, vol. 21, no. 6, pp. 595$599,2007$.

[15] J. D. Raman, M. A. Palese, C. K. Ng, et al., "Handassisted laparoscopic nephroureterectomy for upper urinary tract transitional cell carcinoma," Journal of the Society of Laparoendoscopic Surgeons, vol. 10, no. 4, pp. 432-438, 2006.

[16] J. S. Wolf Jr., A. Dash, B. K. Hollenbeck, W. K. Johnston III, R. Madii, and J. S. Montgomery, "Intermediate followup of hand assisted laparoscopic nephroureterectomy for urothelial carcinoma: factors associated with outcomes," The Journal of Urology, vol. 173, no. 4, pp. 1102-1107, 2005.

[17] G. M. Cannon Jr., T. Averch, J. Colen, S. Morrisroe, O. Durrani, and R. L. Hrebinko Jr., "Hand-assisted laparoscopic nephroureterectomy with open cystotomy for removal of the distal ureter and bladder cuff," Journal of Endourology, vol. 19, no. 8, pp. 973-975, 2005.

[18] S.-D. Chung, C.-Y. Huang, S.-C. Chueh, et al., "Intermediate follow-up of hand-assisted retroperitoneoscopic nephroureterectomy for management of upper urinary tract urothelial carcinoma: comparison with open nephroureterectomy," Urology, vol. 69, no. 6, pp. 1030-1034, 2007.

[19] K. Nakashima, C. Fujiyama, Y. Tokuda, et al., "Oncologic assessment of hand-assisted retroperitoneoscopic nephroureterectomy for urothelial tumors of the upper tract: comparison with conventional open nephroureterectomy," Journal of Endourology, vol. 21, no. 6, pp. 583-588, 2007.

[20] D. Manabe, T. Saika, S. Ebara, et al., "Comparative study of oncologic outcome of laparoscopic nephroureterectomy and standard nephroureterectomy for upper urinary tract transitional cell carcinoma," Urology, vol. 69, no. 3, pp. 457461, 2007.

[21] T. Y. Hsueh, Y.-H. Huang, A. W. Chiu, S. K. Huan, and Y.-H. Lee, "Survival analysis in patients with upper urinary tract transitional cell carcinoma: a comparison between open and hand-assisted laparoscopic nephroureterectomy," BJU International, vol. 99, no. 3, pp. 632-636, 2007.

[22] V. Paolucci, B. Schaeff, M. Schneider, and C. Gutt, "Tumor seeding following laparoscopy: international survey," World Journal of Surgery, vol. 23, no. 10, pp. 989-997, 1999.

[23] I. Ahmed, N. A. Shaikh, and C. R. Kapadia, "Track recurrence of renal pelvic transitional cell carcinoma after laparoscopic nephrectomy," British Journal of Urology, vol. 81, no. 2, p. 319, 1998.

[24] P. Barrett, D. D. Fentie, L. A. Taranger, et al., "Laparoscopic assisted nephroureterectomy (TCC)," Journal of Endourology, vol. 12, p. S103, 1998.

[25] M. Otani, S. Irie, and Y. Tsuji, "Port site metastasis after laparoscopic nephrectomy: unsuspected transitional cell carcinoma within a tuberculous atrophic kidney," The Journal of Urology, vol. 162, no. 2, pp. 486-487, 1999.

[26] A. M. Ong, S. B. Bhayani, and C. P. Pavlovich, "Trocar site recurrence after laparoscopic nephroureterectomy," The Journal of Urology, vol. 170, no. 4, part 1, p. 1301, 2003.

[27] S.-C. J. Chueh, I.-D. Tsaia, and M.-K. Laia, "Solitary portsite metastasis after laparoscopic bilateral nephroureterctomy for transitional cell carcinoma in a renal transplant recipient," Transplantation Proceedings, vol. 36, no. 9, pp. 2697-2698, 2004.

[28] S. Micali, A. Celia, P. Bove, et al., "Tumor seeding in urological laparoscopy: an international survey," The Journal of Urology, vol. 171, no. 6, part 1, pp. 2151-2154, 2004.

[29] Y. Matsui, H. Ohara, K. Ichioka, N. Terada, K. Yoshimura, and A. Terai, "Abdominal wall metastasis after retroperitoneoscopic assisted total nephroureterectomy for renal pelvic cancer," The Journal of Urology, vol. 171, no. 2, part 1, p. 793, 2004.

[30] N. Naderi, J. A. Nieuwenhuijzen, A. Bex, A. Kooistra, and S. Horenblas, "Port site metastasis after laparoscopic nephroureterectomy for transitional cell carcinoma," European Urology, vol. 46, no. 4, pp. 440-441, 2004.

[31] D. W. Strong and H. D. Pearse, "Recurrent urothelial tumors following surgery for transitional cell carcinoma of the upper urinary tract," Cancer, vol. 38, no. 5, pp. 2178-2183, 1976.

[32] T. Kakizoe, J. Fujita, T. Murase, K. Matsumoto, and K. Kishi, "Transitional cell carcinoma of the bladder in patients with renal pelvic and ureteral cancer," The Journal of Urology, vol. 124, no. 1, pp. 17-19, 1980.

[33] J. R. Steinberg and S. F. Matin, "Laparoscopic radical nephroureterectomy: dilemma of the distal ureter," Current Opinion in Urology, vol. 14, no. 2, pp. 61-65, 2004.

[34] H. McDonald, W. E. Upchurch, and C. E. Sturdevant, "Nephro-ureterectomy: a new technique," The Journal of Urology, vol. 67, pp. 804-809, 1952.

[35] C. M. Gonzalez, R. A. Batler, R. A. Schoor, J. C. Hairston, and R. B. Nadler, "A novel endoscopic approach towards resection of the distal ureter with surrounding bladder cuff during hand assisted laparoscopic nephroureterectomy," The Journal of Urology, vol. 165, no. 2, pp. 483-485, 2001.

[36] I. Y. Vardi, J. A. Stern, C. M. Gonzalez, S. Y. Kimm, and R. B. Nadler, "Novel technique for management of distal ureter and en block resection of bladder cuff during hand-assisted laparoscopic nephroureterectomy," Urology, vol. 67, no. 1, pp. 89-92, 2006.

[37] C. Wong and R. J. Leveillee, "Hand-assisted laparoscopic nephroureterectomy with cystoscopic en bloc excision of the distal ureter and bladder cuff," Journal of Endourology, vol. 16, no. 6, pp. 329-332, 2002. 
[38] R. Ko, B. H. Chew, D. R. Hickling, et al., "Transitional-cell carcinoma recurrence rate after nephroureterectomy in patients who undergo open excision of bladder cuff $v$ transurethral incision of the ureteral orifice," Journal of Endourology, vol. 21, no. 7, pp. 730-734, 2007.

[39] D. McDonald, "Intussusception ureterectomy: a method of removal of the ureteral stump at time of nephrectomy without an additional incision," Surgery, Gynecology \& Obstetrics, vol. 97, pp. 565-568, 1953.

[40] B. Giovansili, M. Peyromaure, D. Saïghi, T. Dayma, M. Zerbib, and B. Debré, "Stripping technique for endoscopic management of distal ureter during nephroureterectomy: experience of 32 procedures," Urology, vol. 64, no. 3, pp. 448452,2004

[41] I. S. Gill, J. J. Soble, S. D. Miller, and G. T. Sung, "A novel technique for management of the en bloc bladder cuff and distal ureter during laparoscopic nephroureterectomy," The Journal of Urology, vol. 161, no. 2, pp. 430-434, 1999.

[42] I. S. Gill, G. T. Sung, and M. G. Hobart, "Laparoscopic radical nephroureterectomy for upper tract transitional cell carcinoma: the Cleveland clinic experience," The Journal of Urology, vol. 164, no. 5, pp. 1513-1522, 2000.

[43] A. L. Shalhav, M. D. Dunn, A. J. Portis, A. M. Elbahnasy, E. M. McDougall, and R. V. Clayman, "Laparoscopic nephroureterectomy for upper tract transitional cell cancer: the Washington University experience," The Journal of Urology, vol. 163, no. 4, pp. 1100-1104, 2000.

[44] R. Hattori, Y. Yoshino, M. Gotoh, M. Katoh, O. Kamihira, and Y. Ono, "Laparoscopic nephroureterectomy for transitional cell carcinoma of renal pelvis and ureter: Nagoya experience," Urology, vol. 67, no. 4, pp. 701-705, 2006.

[45] R. Venkatesh, J. Rehman, J. Landman, et al., "Determination of cell viability after laparoscopic tissue stapling in a porcine model," Journal of Endourology, vol. 19, no. 6, pp. 744-747, 2005.

[46] S. F. Matin and I. S. Gill, "Recurrence and survival following laparoscopic radical nephroureterectomy with various forms of bladder cuff control," The Journal of Urology, vol. 173, no. 2, pp. 395-400, 2005.

[47] A. Tsivian, S. Benjamin, and A. A. Sidi, "A sealed laparoscopic nephroureterectomy: a new technique," European Urology, vol. 52, no. 4, pp. 1015-1019, 2007.

[48] D. E. McGinnis, E. J. Trabulsi, L. G. Gomella, and S. E. Strup, "Hand-assisted laparoscopic nephroureterectomy: description of technique," Techniques in Urology, vol. 7, no. 1, pp. 7-11, 2001.

[49] H. Abou El Fettouh, J. J. Rassweiler, M. Schulze, et al., "Laparoscopic radical nephroureterectomy: results of an international multicenter study," European Urology, vol. 42, no. 5, pp. 447452, 2002.

[50] J. A. Brown, S. E. Strup, E. Chenven, D. Bagley, and L. G. Gomella, "Hand-assisted laparoscopic nephroureterectomy: analysis of distal ureterectomy technique, margin status, and surgical outcomes," Urology, vol. 66, no. 6, pp. 1192-1196, 2005.

[51] E. Kurzer, R. J. Leveillee, and V. G. Bird, "Combining hand assisted laparoscopic nephroureterectomy with cystoscopic circumferential excision of the distal ureter without primary closure of the bladder cuff-is it safe?" The Journal of Urology, vol. 175, no. 1, pp. 63-67, 2006.

[52] M. Ozsahin, A. Zouhair, S. Villà, et al., "Prognostic factors in urothelial renal pelvis and ureter tumours: a multicentre rare cancer network study," European Journal of Cancer, vol. 35, no. 5, pp. 738-743, 1999.
[53] K. Steven and A. L. Poulsen, "Radical cystectomy and extended pelvic lymphadenectomy: survival of patients with lymph node metastasis above the bifurcation of the common iliac vessels treated with surgery only," The Journal of Urology, vol. 178, no. 4, pp. 1218-1224, 2007.

[54] T. Kondo, H. Nakazawa, F. Ito, Y. Hashimoto, H. Toma, and K. Tanabe, "Primary site and incidence of lymph node metastases in urothelial carcinoma of upper urinary tract," Urology, vol. 69, no. 2, pp. 265-269, 2007.

[55] T. Kondo, H. Nakazawa, F. Ito, Y. Hashimoto, H. Toma, and K. Tanabe, "Impact of the extent of regional lymphadenectomy on the survival of patients with urothelial carcinoma of the upper urinary tract," The Journal of Urology, vol. 178, no. 4, pp. 1212-1217, 2007.

[56] M. A. Brausi, M. Gavioli, G. De Luca, et al., "Retroperitoneal lymph node dissection (RPLD) in conjunction with nephroureterectomy in the treatment of infiltrative transitional cell carcinoma (TCC) of the upper urinary tract: impact on survival," European Urology, vol. 52, no. 5, pp. 1414-1420, 2007.

[57] I. Cagiannos, "Editorial comment on: retroperitoneal lymph node dissection (RPLD) in conjunction with nephroureterectomy in the treatment of infiltrative transitional cell carcinoma (TCC) of the upper urinary tract: impact on survival," European Urology, vol. 52, no. 5, pp. 1419-1420, 2007.

[58] J. E. Busby and S. F. Matin, "Laparoscopic radical nephroureterectomy for transitional cell carcinoma: where are we in 2007?" Current Opinion in Urology, vol. 17, no. 2, pp. 83-87, 2007.

[59] K. Rose, S. Khan, H. Godbole, J. Olsburgh, and P. Dasgupta, "Robotic assisted retroperitoneoscopic nephroureterectomy-first experience and the hybrid port technique," International Journal of Clinical Practice, vol. 60, no. 1, pp. 12-14, 2006.

[60] D. K. Nanigian, W. Smith, and L. M. Ellison, "Robot-assisted laparoscopic nephroureterectomy," Journal of Endourology, vol. 20, no. 7, pp. 463-465, 2006.

[61] D. S. Finley, O. Melamud, and D. K. Ornstein, "Combined robot-assisted laparoscopic nephroureterectomy and radical prostatectomy," Journal of Endourology, vol. 21, no. 4, pp. 411414, 2007.

[62] D. Eun, A. Bhandari, R. Boris, C. Rogers, M. Bhandari, and M. Menon, "Concurrent upper and lower urinary tract robotic surgery: strategies for success," BJU International, vol. 100, no. 5, pp. 1121-1125, 2007. 


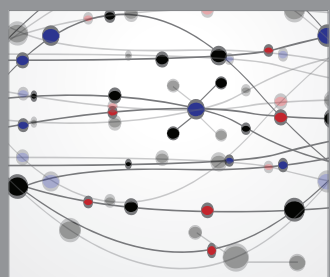

The Scientific World Journal
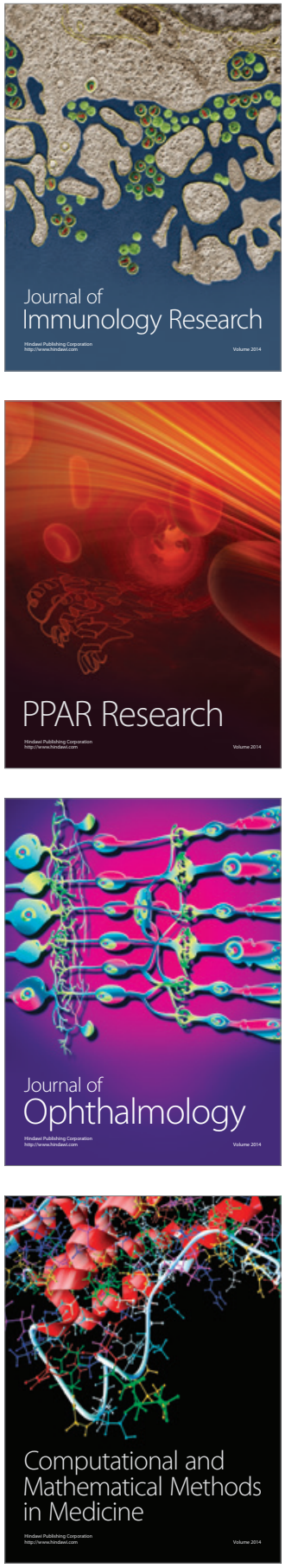

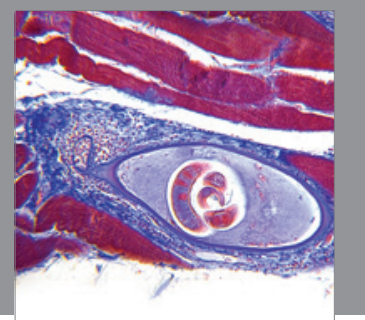

Gastroenterology

Research and Practice
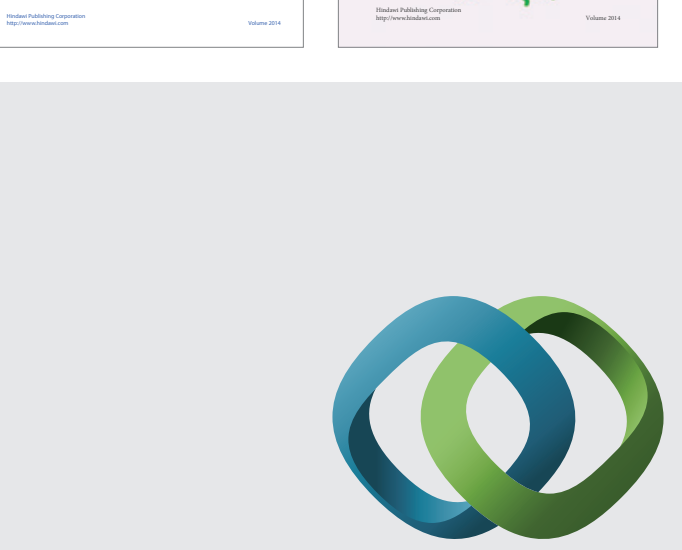

\section{Hindawi}

Submit your manuscripts at

http://www.hindawi.com
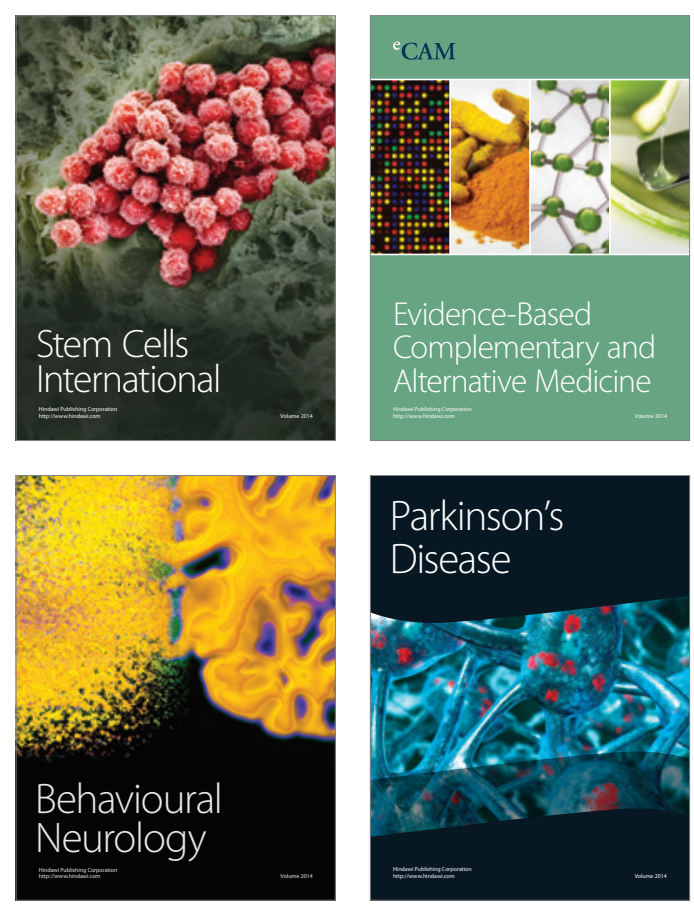

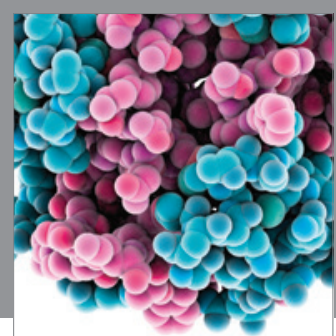

Journal of
Diabetes Research

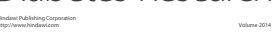

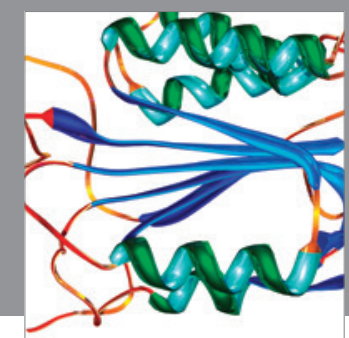

Disease Markers
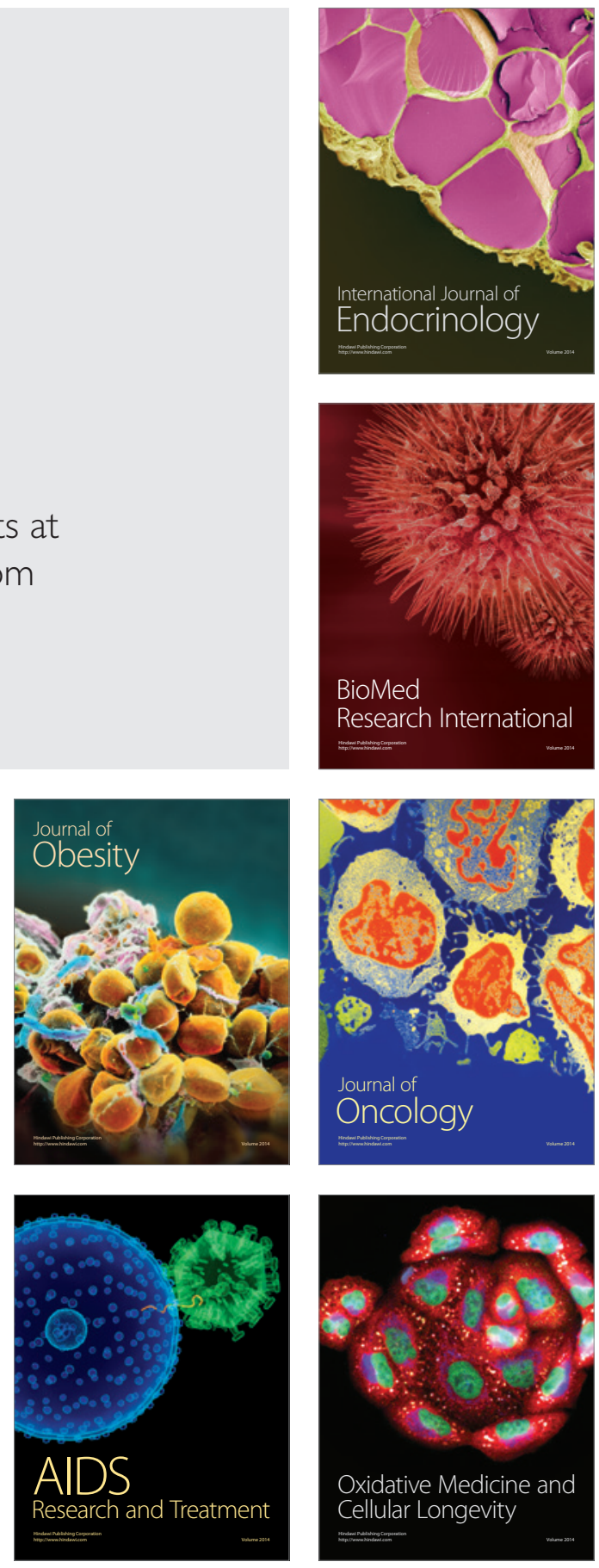